\title{
PERFORMANCE MEASUREMENT OF INSURANCE COMPANIES BY USING BALANCED SCORECARD AND ANP
}

\author{
Ronay $\mathrm{Ak}^{*}$ \\ Istanbul Technical University, \\ Faculty of Management \\ Istanbul, Turkey \\ Email: $\underline{\text { akr@itu.edu.tr }}$ \\ Başar Öztayşi \\ Istanbul Technical University, \\ Faculty of Management \\ Istanbul, Turkey \\ Email: oztaysib@itu.edu.tr
}

\begin{abstract}
The balanced scorecard (BSC) is a strategic planning and management system that has wide applications in manufacturing and service industries. The main goals of BSC are to align business activities to the vision and strategy of the organization, improve internal and external communications, and monitor organization performance against strategic goals. In this study, performance measurement is defined as an evaluation of the past activities with respect to the desired goals. First a balanced scorecard based performance measurement system is proposed for insurance companies. Then perspectives that were obtained from BSC approach are quantified by Analytical Network Process (ANP).

Key words: analytical network process, balanced scorecard, insurance company, performance measurement.
\end{abstract}

\section{Introduction}

Performance Measurement Systems (PMS) plays a key role for business organizations. PMS aims to implement a strategy for the organization. Many researches have shown that conventional financially based performance measurement systems have failed to measure and integrate all the factors critical to success of a business. To deal with the new environment, new PMS have been proposed such as BSC, Activity Based Cost System, the SMART system, etc (Suwignjo, et al., 2000).

The balanced scorecard (BSC) is a strategic planning and management system that has wide applications in manufacturing and service industries. The main goals of BSC are to align business activities with the vision and strategy of the organization, improve internal and external communications, and monitor organization performance against strategic goals. It was first introduced by Kaplan and Norton in 1992.

The balanced scorecard approach generally split strategic measures into one of the following: outcome or driver measures, financial or non-financial measures, and internal or external measures (Gautreau, et al., 2001). Using these different types of measures, the scorecard measures organizational performance in terms of four balanced perspectives: financial, customers, internal business process, and learning and growth (Kaplan et al., 1996). 
The aim of this paper is to apply a BSC based PMS to insurance companies. First a questionnaire was prepared based on the four perspectives mentioned above and send the three leading insurance companies in Turkey. The companies were asked to score perspectives according to their importance level and compare perspectives and sub-criteria between each others. Then, questionnaire results were evaluated to select appropriate performance measures under each of perspectives. Finally, by using the selected criteria and sub-criteria an ANP model was designed and results were discussed in conclusion section.

The remainder of this paper has been organized as follows: In section 2, we review existing performance measurement models from the literature. Then, we present our proposed model for insurance companies in Section 3. Finally, we summarize our study by some concluding remarks in section 4 .

\section{Literature Review}

Recently studies about company performance measurement system not only focus on financial measurements but also non-financial measurements. There are both quantitative and qualitative methods presented to measure organization performance.

Suwingjo et al. (2000) presented a quantitative based performance measurement (PM) approach (QMPMS) with four steps to describe works at the Centre for Strategic Manufacturing, University of Strathclyde. First, they elaborated the factors affecting performance and their relationships. In the second phase, cause and effect diagrams were used to identify the hierarchical structure of the factors. After this step, a tree diagram was used to give a clearer picture of the hierarchical structure. Finally, Analytic Hierarchy Process (AHP) was used to quantify the relative effects of the factors (direct, indirect, and combined).

Bourne et al. (2000), proposed to divide the development of performance measurement systems into three main phases: the design, the implementation and the use of performance measures. Then, these phases also split into various numbers of subdivisions. They pointed that measures are derived from strategies.

Lohman et al. (2004), provided empirical results on improving performance measurement systems to support supply chain management, using a case study methodology. They compared these empirical results with the literature and obtained new theoretical insights. Then, these findings were based on a case study at European Operations of Nike.

Folan et al. (2005) described the evolution of performance measurement in four sections: recommendations, frameworks, systems and inter-organizational performance measurement. They also compared various performance measurement systems according to their framework typology and dimensions of measurement. Framework typology was classified into two classes: structural and procedural. They also emphasized the importance of inter-organizational PM policy for the future of PM.

Although there are many studies on performance measurement systems for organizations, there are not enough applications on insurance companies. Hence, this study focused on performance measurement of insurance companies. 


\section{Proposed Model}

As mentioned before, this study aims to present a model and apply it to insurance companies to obtain a performance score per period. Hence, we need quantitative data related to the companies' performance. Questionnaires enable us to gather quantitative data related to the companies. After questionnaire results, we selected following balanced perspectives and performance measures:

Financial Perspectives (F)

- Total revenue $\left(\mathrm{F}_{1}\right)$

- Cost reduction percentage $\left(\mathrm{F}_{2}\right)$

- Profit rate (percentage) $\left(\mathrm{F}_{3}\right)$

- Return on investment (percentage) $\left(\mathrm{F}_{4}\right)$

Customer Perspectives (C)

- Customer satisfaction rate (percentage) $\left(\mathrm{C}_{1}\right)$

- Cross selling percentage $\left(\mathrm{C}_{2}\right)$

- New customer acquisition rate (percentage) $\left(\mathrm{C}_{3}\right)$

- Customer retention rate (percentage) $\left(\mathrm{C}_{4}\right)$

Internal Business Process Perspectives (P)

- Number of new products $\left(\mathrm{P}_{1}\right)$

- Service error rate (percentage) $\left(\mathrm{P}_{2}\right)$

- Mean-time response to a service call (hours) $\left(\mathrm{P}_{3}\right)$

- Customer complaints rate (percentage) $\left(\mathrm{P}_{4}\right)$

Learning and Growth Perspectives (L)

- Implementation rate for strategic plans (percentage) $\left(\mathrm{L}_{1}\right)$

- Mean-time to re-skilling per employee (hours) $\left(\mathrm{L}_{2}\right)$

- Investment rate in information technology and systems $\left(\mathrm{L}_{3}\right)$

- Customer satisfaction rate (percentage) $\left(\mathrm{L}_{4}\right)$

We designed an ANP model by using these criteria and sub-criteria. Figure I illustrate our ANP model's logical design. Our goal is to calculate corporate performance score. Then we formed pair wise comparison matrixes, where the number in the $i_{t h}$ row and $j_{t h}$ column gives the relative importance of $\mathrm{O}_{\mathrm{i}}$ as compared with $\mathrm{O}_{\mathrm{j}}$, by using a 1-9 scale with

$1=$ if the two objects are equal in importance

$3=$ if $\mathrm{O}_{\mathrm{i}}$ is weakly more important than $\mathrm{O}_{j}$

$5=$ if $\mathrm{O}_{\mathrm{i}}$ is strongly more important than $\mathrm{O}_{\mathrm{j}}$

$7=$ if $\mathrm{O}_{\mathrm{i}}$ is very strongly more important than $\mathrm{O}_{\mathrm{j}}$

$9=$ if $\mathrm{O}_{\mathrm{i}}$ is absolutely more important than $\mathrm{O}_{\mathrm{j}}$

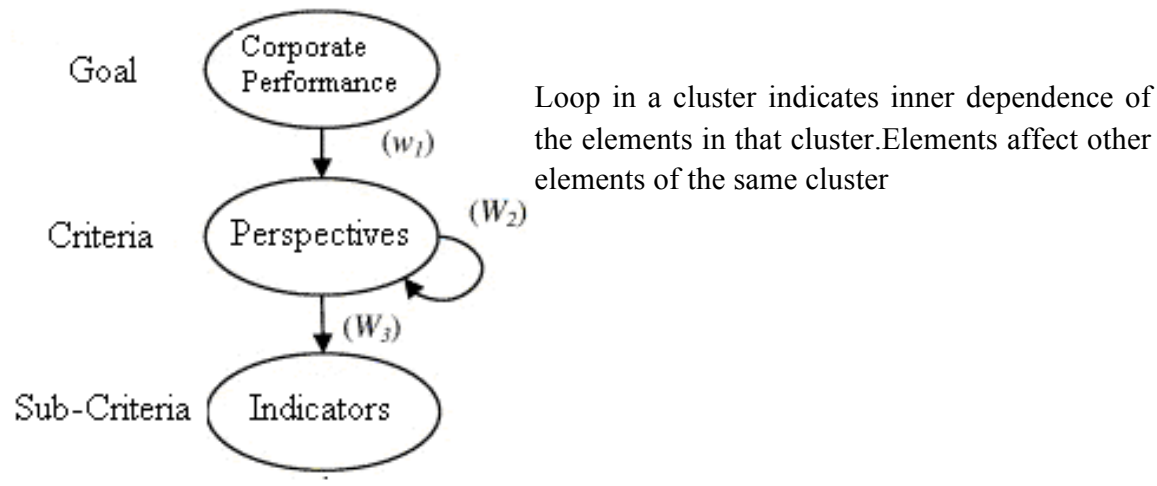


Fig.1. ANP model's logical design

Table I shows a comparison matrix of perspectives. These matrixes were filled out according to expert opinions. In our ANP model as indicated in Figure 2, financial perspective depends on customer and internal business process perspectives. Customer perspective also depends on internal business process and learning and growth perspectives.

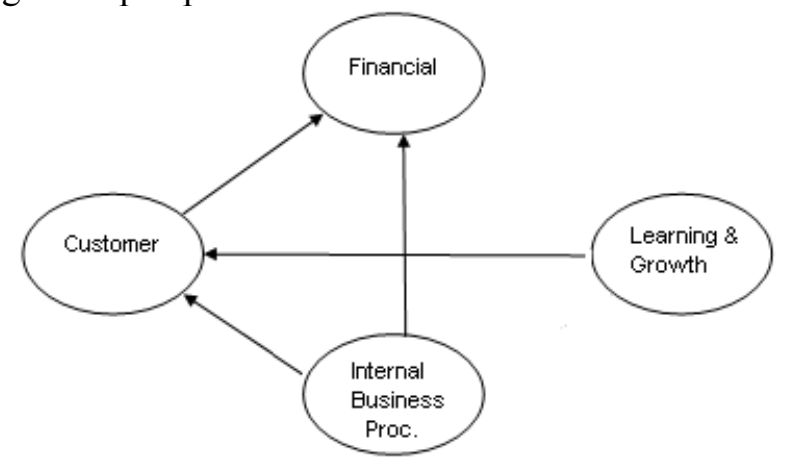

Fig.2. Dependence of Perspectives

Table 1. Comparison matrix for perspectives

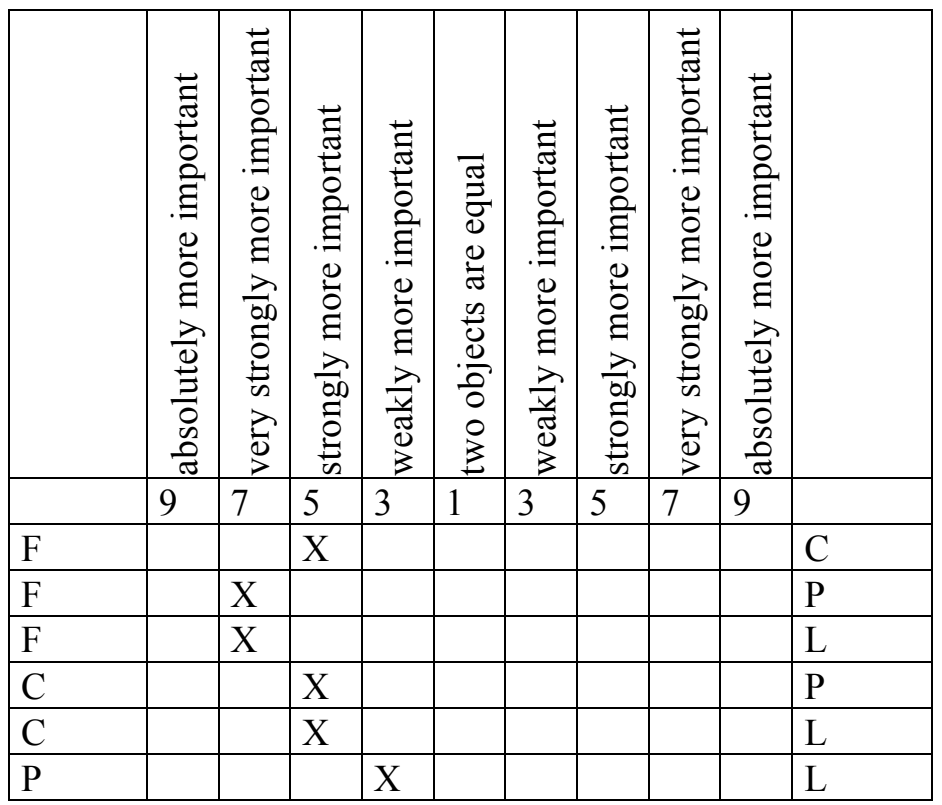

After we had compared criteria and sub-criteria, we obtained weights of each sub-criteria illustrated as Table 2. We also calculated ratings by using Analytical Hierarchy Process (AHP). As shown in Table 2 , customer complaint rate and total revenue influence the goal more than others.

Table 2. Sub-criteria ratings

\begin{tabular}{|l|l|l|}
\hline & ANP & AHP \\
\hline P4 & 0.17074 & 0.03558 \\
\hline F1 & 0.10239 & 0.20478 \\
\hline P1 & 0.08998 & 0.01875 \\
\hline P3 & 0.08344 & 0.01739 \\
\hline C1 & 0.08283 & 0.09943 \\
\hline
\end{tabular}




\begin{tabular}{|l|l|l|}
\hline F3 & 0.0764 & 0.15279 \\
\hline F4 & 0.06933 & 0.13865 \\
\hline F2 & 0.06679 & 0.13357 \\
\hline P2 & 0.06203 & 0.01293 \\
\hline C3 & 0.06117 & 0.07343 \\
\hline L4 & 0.04679 & 0.02807 \\
\hline C4 & 0.04063 & 0.04877 \\
\hline L2 & 0.0201 & 0.01205 \\
\hline C2 & 0.01228 & 0.01474 \\
\hline L3 & 0.01163 & 0.00697 \\
\hline L1 & 0.00348 & 0.00209 \\
\hline
\end{tabular}

We also calculated the inner ratings of elements in each cluster. As shown in Table 3, similar to previous rating results, $\mathrm{F}_{1}$ and $\mathrm{P}_{4}$ have highest rating inside their own clusters.

Table 3. Sub-criteria ratings depending on their own cluster

\begin{tabular}{|l|l|}
\hline F1 & 0.325141 \\
\hline F2 & 0.212092 \\
\hline F3 & 0.242609 \\
\hline F4 & 0.220158 \\
\hline
\end{tabular}

\begin{tabular}{|l|l|}
\hline C1 & 0.420649 \\
\hline C2 & 0.062364 \\
\hline C3 & 0.31065 \\
\hline C4 & 0.206338 \\
\hline
\end{tabular}

\begin{tabular}{|l|l|}
\hline L1 & 0.042439 \\
\hline L2 & 0.245122 \\
\hline L3 & 0.141829 \\
\hline L4 & 0.57061 \\
\hline
\end{tabular}

\begin{tabular}{|l|l|}
\hline P1 & 0.221522 \\
\hline P2 & 0.152712 \\
\hline P3 & 0.205421 \\
\hline P4 & 0.420345 \\
\hline
\end{tabular}

We finally proposed a model to calculate a performance score by using ratings obtained from the ANP. However, because of lack of data, we explained our model on a hypothetical example. While the importance ratings represented in Table 4 are calculated using ANP method, the values of measures are not real-time organizational data. Min and Max columns reflect organization's minimum and maximum quantitative goals related to the performance measures.

Table 4 represents the calculation of performance for each period. AS a summary the calculations take place in these steps:

i. $\quad$ The importance ratings are calculated using ANP method (column 2).

ii. The goals are defined in terms of minimum and maximum values (column 3 and 4).

iii. The measured values for each criterion are determined (column 5 and 7).

iv. The measured values are normalized using minimum and maximum values (defined in step ii.) (Column 6 and 8).

v. Each criterion score is calculated with the related importance rating in order to find the weighted score (column 9 and 10).

vi. The weighted scores are summed which represents the periods over all performance score

Table 4. Calculation performance scores periodically by using proposed model

\begin{tabular}{|l|l|l|l|l|l|l|l|l|l|l|}
\hline & Ratings & Min & Max & Period I & Period I score & Period II & $\begin{array}{l}\text { Period II } \\
\text { score }\end{array}$ & $\begin{array}{l}\text { Weighted } \\
\text { Score for } \\
\text { Period I }\end{array}$ & $\begin{array}{l}\text { Weighted } \\
\text { Score for } \\
\text { Period II }\end{array}$ & Difference \\
\hline C1 & 0.08 & $0 \%$ & $100 \%$ & $45 \%$ & 45.00 & $60.00 \%$ & 60.00 & 3.73 & 4.97 & 1.24 \\
\hline C2 & 0.01 & $0 \%$ & $30 \%$ & $20 \%$ & 66.67 & $22.00 \%$ & 73.33 & 0.82 & 0.90 & 0.08 \\
\hline C3 & 0.06 & $0 \%$ & $25 \%$ & $15 \%$ & 60.00 & $16.00 \%$ & 64.00 & 3.67 & 3.91 & 0.24 \\
\hline C4 & 0.04 & $0 \%$ & $100 \%$ & $80 \%$ & 80.00 & $85.00 \%$ & 85.00 & 3.25 & 3.45 & 0.20 \\
\hline F1 & 0.10 & 300000 & 400000 & 380000 & 80.00 & 386000 & 86.00 & 8.19 & 8.81 & 0.61 \\
\hline
\end{tabular}




\begin{tabular}{|c|c|c|c|c|c|c|c|c|c|c|}
\hline F2 & 0.07 & $0 \%$ & $10 \%$ & $2 \%$ & 20.00 & $3.00 \%$ & 30.00 & 1.34 & 2.00 & 0.67 \\
\hline F3 & 0.08 & $0 \%$ & $17 \%$ & $12 \%$ & 70.59 & $14.00 \%$ & 82.35 & 5.39 & 6.29 & 0.90 \\
\hline F4 & 0.07 & $0 \%$ & $22 \%$ & $10 \%$ & 45.45 & $14.00 \%$ & 63.64 & 3.15 & 4.41 & 1.26 \\
\hline L1 & 0.00 & $0 \%$ & $100 \%$ & $56 \%$ & 56.00 & $60.00 \%$ & 60.00 & 0.19 & 0.21 & 0.01 \\
\hline L2 & 0.02 & 0 & 30 & 9 & 31.50 & 13 & 43.33 & 0.63 & 0.87 & 0.24 \\
\hline L3 & 0.01 & $0 \%$ & $10 \%$ & $2 \%$ & 20.00 & $3.00 \%$ & 30.00 & 0.23 & 0.35 & 0.12 \\
\hline L4 & 0.05 & $0 \%$ & $100 \%$ & $90 \%$ & 90.00 & $80.00 \%$ & 80.00 & 4.21 & 3.74 & -0.47 \\
\hline P1 & 0.09 & 0 & 3 & 1 & 33.33 & 1 & 33.33 & 3.00 & 3.00 & 0.00 \\
\hline P2 & 0.06 & $100 \%$ & $0 \%$ & $10 \%$ & 90.00 & $85.00 \%$ & 15.00 & 5.58 & 0.93 & -4.65 \\
\hline P3 & 0.08 & 48 & 2 & 36 & 26.09 & 24 & 52.17 & 2.18 & 4.35 & 2.18 \\
\hline \multirow[t]{3}{*}{ P4 } & 0.17 & $100 \%$ & $0 \%$ & $20 \%$ & 80.00 & $18.00 \%$ & 82.00 & 13.66 & 14.00 & 0.34 \\
\hline & & & & & & & & $\begin{array}{l}\text { Perform } \\
\text { ance } \\
\text { Score } \\
\text { for } \\
\text { Period I }\end{array}$ & $\begin{array}{l}\text { Perform } \\
\text { ance } \\
\text { Score } \\
\text { for } \\
\text { Period II }\end{array}$ & \\
\hline & & & & & & & & 59.22 & 62.20 & \\
\hline
\end{tabular}

The proposed model enables the managers to

- Evaluate performance difference in each period separately. Since the measures used in the model are in different kinds it is nearly impossible to evaluate or benchmark the observed performance with each other. But in the model, each observed value is normalized according to the goals so that a performance score is calculated which can be used to comparison.

- Observe the improvements that take place between the measurement periods. In the last column of Table 4 , the performance differences in each measure are calculated. This column can be interpreted in order to find which measures are going good and which are not. For example, L4 and P2 measures are performed worse in the second period compared to the first period. On the other hand, $\mathrm{P} 3$ represents the major improvement between 2 periods.

- Calculate a single performance level which indicates the overall performance of the organization. The main goal of the model is to calculate an overall performance score this score is calculated using weighted scores. While the Period I represents 59.22, the Period II represents 62.20 which means nearly $\% 3$ increase is observed in the organizational performance.

- Compare the importance of the measures. Table 2 represents the importance levels of each measure. These importance levels are later used in the calculations but they can be used to bench mark the measures. While P4, F1, and P1 are the most important measures, L3 and L1 are the least important ones.

\section{Conclusion}

The aim of this paper is to apply a BSC based PMS to insurance companies. Perspectives and their sub-criteria were acquired from the literature. Then experts were asked to rate them in order to select appropriate measures for insurance sector. With selected criteria and sub-criteria an ANP model is designed.

ANP helps us to perceive the importance level of criteria on our goal. Table 2 represents both the AHP and the ANP results of each criterion. In a model that we omit the inner dependence between the perspectives, financial measures $(\mathrm{F} 1, \mathrm{~F} 2, \mathrm{~F} 3, \mathrm{~F} 4)$ are shown as the most important measures. But both the literature and the practitioners declare that there is dependence between the perspectives. ANP method helps us to reflect the dependence to the model. Results show that, although it is very 
important, financial perspective is not enough to explain an insurance company's performance. Internal Business Process Perspectives have a considerable effect on performance.

Moreover, by using ratings we calculated periodic performance score. We believe that this score helps organizations to qualify their outcomes more accurately. Besides using this method organizations can easily calculate their performance in future periods and compare the results with the pervious ones.

We used BSC method in this study due to increases in competition and the need to implement corporate strategy. BSC enables managers to execute organization's strategies and vision successfully. 


\section{REFERENCES}

Suwignjo, P., Bititci, U.S. \& Carrie A. S. (2000). "Quantitative models for performance measurement system”, Int. J. Production Economics, 64, 231-241.

Gautreau, A. \& Kleiner, B. H. (2001). "Recent trends in performance measurement systems-the balanced scorecard approach", Management Research News, 24, 153-156.

Folan, P. \& Browne, J. (2005). “A review of performance measurement: Towards performance management", Computers in Industry 56, 663-680.

Lohman, C., Fortuin, L. \& Wouters, M. (2004) "Designing a performance measurement system: A case study", European Journal of Operational Research, 156, 267-286.

Bourne, M., Mills, J., Wilcox, M., Neely, A. \& Platts, K. (2000). "Designing, implementing and updating performance measurement systems", International Journal of Operations \& Production Management 20, 751-774.

Kaplan, R. S. \& Norton, D. P. (1996). “The balanced scorecard: translating strategy into action”, Harvard Business Press. 